\title{
Time to choose the right site for a fusion reactor
}

\author{
Europe is ready, willing and able to host the ITER, so let's get on and meet the challenge.
}

Sir - Your Editorial "Time for Japan to shine?” (Nature 427, 763; 2004) clearly presents the necessity of building ITER, formerly the International Thermonuclear Experimental Reactor. But I must say — as a European negotiator in the ITER talks that, in trying not to be Euro-parochial, you do injustice to the role played by Europe in controlled fusion and in ITER.

Indeed, there is no mention of Europe's uncontested leading role in fusion, nor of the fact that data from the largest and bestperforming machine, the Joint European Torus (JET) — which is above par proved essential in designing ITER and in creating our confidence that ITER will meet its aims. The European Union (EU), more than any other partner, has provided constant, substantial support to the ITER project since its inception. The remarkable support given by Japan should also be mentioned at this point, although in terms of financial and human resources it has taken place at a significantly lower level.

Since July 2001, the EU has kept the project alive by spending $€ 160$ million
(US\$197 million), at a time when the United States had left the project. Your assertion that political and public support for ITER is less than whole-hearted in Europe does not rest on facts. The European Council of Ministers decided unanimously to present Cadarache, France, as the site, with reference to the financial estimate of costs made by the European Commission. The people living around Cadarache support ITER, and the region of Provence-Alpes-Côte d'Azur unanimously agreed to pay $€ 447$ million towards its costs. Although you say that Japan has a greater commitment to future energy sources, the legal framework for licensing ITER does not yet exist in Japan whereas the licensing procedure has already started in Cadarache.

Nature correctly states that, if Europe's case is technically strongest, then Japan's compensation should include international contribution to an upgrade of the JT-60 tokamak to achieve critical science on the way to Demo, the engineering prototype reactor. But the EU negotiators deplore the fact that the United States and Japan refuse a direct and objective comparison of the technical assets of the European and Japanese sites. Is this because Cadarache meets most of the nine criteria better?

For the above reasons, we feel that the ITER partners should now quickly decide to locate ITER in Cadarache, and that this decision should be accompanied by a commitment at the highest political level to implement a broader approach to fusion energy, well balanced between the needs of the programme and the capabilities of the partners. The world programme could include, in addition to ITER, the technology programme required for a commercial reactor (for example, a material-testing facility) and joint exploitation of 'satellite' tokamak facilities. This coherent approach would be the best way of getting on as quickly as possible with one of the most important world challenges of this century. Paul Vandenplas

Consultative Committee Euratom-Fusion, and Ecole Royale Militaire, 30 avenue de la Renaissance, 1000 Brussels, Belgium

\section{US science has never been more coherent}

Sir - Your Editorial "Budget let-downs" (Nature 427, 571; 2004) paints a picture of US science funding that differs astoundingly from reality. The trajectory of $\mathrm{R} \& \mathrm{D}$ growth that you call "lacklustre" has risen more rapidly during the past four years than at any time in the past three decades: an average of $10 \%$ per year under the current administration. At US $\$ 132$ billion, the proposed $2005 \mathrm{R} \& \mathrm{D}$ budget is at an alltime high and consumes a greater fraction of the domestic discretionary budget than at any time since the height of the Apollo space programme.

The proposals for priority programmes at the National Institutes of Health, the National Science Foundation, NASA and other agencies are above current and anticipated inflation levels and are well above the $0.5 \%$ increase for other parts of the non-defence discretionary budget. Priorities are well defined, established with wide interagency planning, and generally supported across agencies.

The proposed reorientation of NASA integrates robotic and human exploration, strengthens the scientific rationale for human spaceflight, and sets long-term budget guidelines that will protect NASA science from overruns elsewhere. The Hubble Telescope decision is not connected with this reorientation, but strongly related to safety issues identified by the Columbia Accident Investigation Board.

The United States leads the world in providing resources to pursue critical research in areas such as environment, energy and global health. Some programmes have been reduced or eliminated on the basis of their performance record; others have been enhanced. Investments in areas of research related to domestic security, including emerging infectious diseases, belie your puzzling statement that "pressing scientific challenges ... evidently cannot attract sufficient resources."

Equally puzzling is your failure to discover direction and coordination in a budget shaped by specific interagency initiatives for security, space exploration, climate change, nanotechnology, information technology and energy initiatives. These are identified so explicitly in the budget materials that one marvels at your statement: "No sign of that this year". On the contrary, the coherence and strength of US science has never been greater or more productive.

John H. Marburger

Office of Science and Technology Policy,

Executive Office of the President,

Washington, DC 20502, USA

\section{More to consider about European research body}

Sir - The Royal Society's working paper on the European science base, discussed in your News story "Europe warned against research council” (Nature 427, 184; 2004), is much more positive about the creation of a proposed European Research Council (ERC) than you suggest. We do express reservations about certain proposals, but this does not mean that a more focused and prioritized version would not benefit research within the European Union (EU).

One of the main reasons that an ERC has been proposed is to increase spending on research and development in the EU, to close the gap with the United States. However, $90 \%$ of this gap is due to differences in business expenditure, so the potential creation of an ERC must not divert attention from this problem.

Our paper (www.royalsoc.ac.uk/policy) highlights other issues, including gaps in knowledge, that should be considered. We are studying proposals in the final Mayor report (www.ercexpertgroup.org), released on 15 December 2003, and hope that they will stimulate an informed wider debate. Julia Higgins The Royal Society, 6-9 Carlton House Terrace, London SW1Y 5AG, UK 